\title{
ANALISIS EFEKTIVITAS MESIN COOLING TOWER MENGGUNAKAN RANGE AND APPROACH
}

\author{
Ahmad Muhsin' ${ }^{1}$ Zicko Pratama ${ }^{2}$ \\ Program Studi Teknik Industri \\ Jurusan Teknik Industri Fakultas Teknik Industri \\ Universitas Pembangunan Nasional Veteran Yogyakarta \\ Jl. Babarsari 2 Tambakbayan Yogyakarta 55281 \\ email : ahmad.muhsin@upnyk.ac.id
}

\begin{abstract}
ABSTRAK
Cooling tower diperlukan di industri pembangkit listrik tenaga panas bumi untuk sirkulasi air pendingin dengan cara mengontakkan dengan gas tak jenuh sehingga sebagian dari zat cair itu akan menguap dan suhu zat cair turun PT Star Energy Geothermal Wayang Windu Ltd menggunakan mesin Cooling tower untuk melakukan pendinginan. untuk mengetahui performansi kemampuan cooling tower yang dimiliki maka diperlukan pengukuran efektivitas.

Penelitian ini bertujuan untuk menganalisis efektivitas pendinginan, pengukuran efektivitas dilakukan dengan nilai approach dan range. Range merupakan perbedaan atau jarak antar temperature air masuk dan keluar menara pendingin. Approach adalah perbedaan suhu air dingin keluar menara pendingin dan suhu wetbulb ambient. Metode yang digunakan untuk mengukur performansi Cooling Tower menggunakan metode Overall Equipment Effectivenesss untuk mendapatkan nilai availability, performance efficiency, dan rate of quality.

Dari hasil penelitian diperoleh nilai rata-rata OEE mesin cooling tower sebesar > 85\% yang berarti telah memenuhi standar world class dan layak untuk dipergunakan, beberapa titik memiliki nilai kurang dari standar dengan nilai terendah $81 \%$ disebabkan karena lamanya waktu downtime. Perusahaan perlu menerapkan perawatan preventif yang rutin dan tepat waktu untuk mempertahankan performansi Cooling Tower.
\end{abstract}

Kata Kunci: Performansi, Cooling Tower, Overall Equipment Effectiveness

\section{PENDAHULUAN}

Listrik merupakan suatu kebutuhan yang sangat diperlukan masyarakat. Segala aktifitas selalu berhubungan dengan pemanfaatan energi listrik. Untuk pembangkitanya sendiri di Indonesia, listrik dapat dihasilkan dari pemanfaatan batu bara, minyak bumi, air,angin serta panas bumi. Semua sumber energi tersebut tersedia melimpah di Indonesia.Untuk panas bumi atau geotermal memiliki potensi yang sangat besar untuk dikembangkan dan dapat dimanfaatkan untuk skala besar. Energi geotermal dihasilkan dari inti perut bumi akibat terjadinya aktivitas magma.

Cooling tower dewasa ini sangat diperlukan di tiap industri khususnya industri Pembangkit listrik tenaga panas bumi dalam rangka pelaksanaan untuk efisiensi dan konversi energi dimana digunakan suatu alat atau unit yang digunakan untuk sirkulasi air pendingin. Air pendingin yang berasal dari alat atau sistem penukar panas didinginkan di menara pendingin dengan cara mengontakkan dengan udara yang dilewatkan bila zat cair panas dikontakkan dengan gas tak jenuh, sebagian dari zat cair itu akan menguap dan suhu zat cair akan turun. Penurunan suhu zat cair demikian biasanya merupakan tujuan dari berbagai operasi kontak gas dan zat cair, lebih - lebih kontak udara - gas. Fungsi cooling tower adalah memproses air atau cooling tower yang panas menjadi air dingin, sehingga dapat digunakan kembali.

Penelitian yang dilakukan di Star Energy Geothermal Wayang Windu Ltd berkaitan dengan pengukuran nilai efektivitas pendinginan mesin Cooling tower unit 1 bertujuan untuk menganalisis efektivitas pendinginan pada jam tertentu. Pengukuran efektivitas dilakukan dengan memperhatikan dua hal penting yaitu nilai approach dan nilai range. Range merupakan perbedaan atau jarak antar temperature air masuk dan keluar menara pendingin,Jadi nilai Range yang tinggi berarti bahwa menara pendingin telah mampu 
menurunkan suhu air secara efektif dan kinerjanya baik, Sedangkan Approach adalah perbedaan suhu air dingin keluar menara pendingin dan suhu wetbulb ambient, semakin rendah approach semakin baik kinerja Cooling tower.

\section{LANDASAN TEORI}

Cooling Tower adalah alat penukar kalor yang berfungsi mendinginkan air dengan mengontakannya ke udara sehingga menguapkan sebagian kecil dari air (Handoyo, 2015). Menara pendingin merupakan suatu peralatan yang digunakan untuk menurunkan suhu aliran air dengan cara mengekstraksi panas dari air dan mengemisikannya ke atmosfir. Menara pendingin menggunakan penguapan dimana sebagian air diuapkan ke aliran udara yang bergerak dan kemudian dibuang ke atmosfir (Effendi and Wirza, 2013).

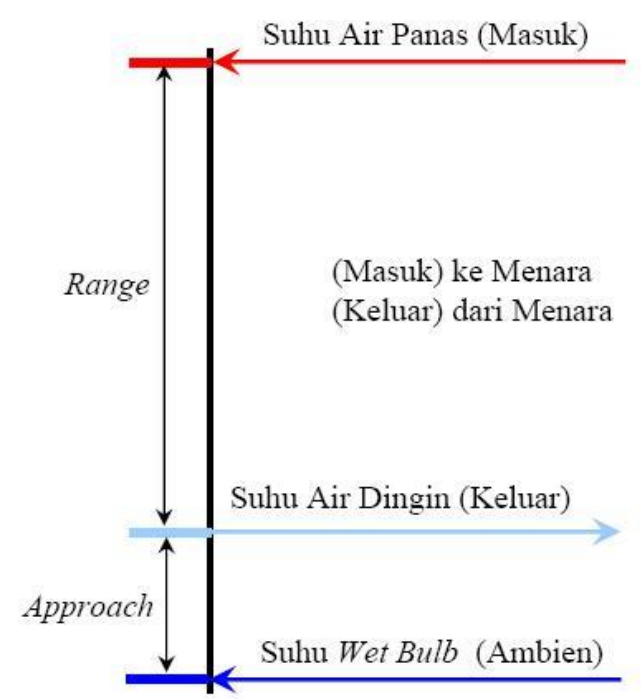

Gambar 2.1 Range dan approach temperatur

Cooling Tower (Handoyo, 2015)

Pemeliharaan atau perawatan dalam suatu industri merupakan salah satu faktor penting dalam mendukung proses produksi, oleh karena itu proses produksi harus didukung oleh peralatan yang siap bekerja setiap saat dan handal (Hapsari, Amar and Rahadian, 2012). Overall Equipment Effectiveness (OEE) merupakan salah satu aplikasi dari program Total Productive Maintenance (TPM) yang digunakan sebagai alat untuk menentukan tingkat efektivitas mesin (Wahyuni, 2015). Pengukuran Equipment Effectiveness (OEE) menggunakan dasar
3 rasio yaitu : availability ratio, performance ratio, dan Quality ratio (Muhsin, 2016). Dengan mengetahui hal tersebut, perusahaan juga dapat melakukan perbaikan atau pencegahan kerusakan yang mungkin akan terjadi agar dapat meningkatkan produktivitas (Ningrum and Muhsin, 2016).

Performa menara pendingin dievaluasi untuk membahas approach dan range operasi pada nilai rancangan, indetifikasi area pemborosan energi, dan juga untuk sarana perbaikan (Handoyo, 2015). Dengan begitu dapat dilakukan perencanaan perawatan mesin yang tepat (preventive maintenance) sehingga dapat mengurangi jumlah kerusakan mesin yang terjadi secara tiba-tiba (Muhsin and Syarafi, 2018). Pengukuran waktu adalah pekerjaan mengamati dan mencatat waktuwaktu kerjanya baik setiap elemen ataupun siklus dengan menggunakan alat-alat yang telah disiapkan (Ade and Muhsin, 2017).

Suplai air sejuk (dingin) yang tepat dan kontinyu maka Cooling Tower sebgai alat Penukar Kalor tersebut dapat bekerja sesuai dengan spesifikasi dan kondisi yang diharapkan, selain itu biaya yang dikeluarkan akan menjadi lebih efektif dan energi yang dikeluarkan lebih efisien (Yulianto and Urbiantoro, 2013). Menara pendingin disimpan dalam ruangan tertutup dimaksudkan untuk menghindari fluktuasi suhu dan kelembaban yang terlalu ekstrim (Wibisono, 2005).

\section{METODOLOGI PENELITIAN}

Penelitian dilakukan di Star Energy Geothermal Wayang Windu Ltd., Pangalengan, Bandung pada Departemen Production. Penelitian ini diperlukan data yang mendukung, data yang digunakan adalah:

1. Suhu udara wetbulb

2. Suhu air masuk (inlet)

3. Suhu air keluar (outlet)

4. Suhu udara masuk

5.

Data yang diperoleh dilakukan pengolahan dengan cara:

1. Perhitungan Range, yaitu perbedaan antara temperature air masuk dan keluar Cooling tower, dengan menggunakan rumus perhitungan adalah sebagai berikut:

Range $\left({ }^{\circ} \mathrm{C}\right)=$ temperatur air masuk $\left({ }^{\circ} \mathrm{C}\right)-$ temperatur air keluar $\left({ }^{\circ} \mathrm{C}\right)$ 
2. Perhitungan Approach, yaitu perbedaan antara temperatur air dingin keluar menara pendingin dan temperatur wet bulb ambien, dengan menggunakan rumus perhitungan adalah sebagai berikut:

Approach $\left({ }^{\circ} \mathrm{C}\right)=$ temperatur air keluar $\left({ }^{\circ} \mathrm{C}\right)$ temperatur wet bulb $\left({ }^{\circ} \mathrm{C}\right)$

3. Perhitungan Efektivitas pendinginan, merupakan perbandingan antara range dan range ideal. Semakin tinggi perbandingan ini, maka semakin tinggi efektivitas pendinginan suatu menara pendingin,dengan menggunakan rumus perhitungan adalah sebagai berikut:

Efektivitas $(\%)=\frac{\text { Range }}{(\text { Range }+ \text { Approach })} \times 100$

4. Nilai Overall Equipment Effectiveness (OEE) dihitung dengan cara mengalikan ketiga factor tersebut sehingga rumus OEE yaitu

$\mathrm{OEE}=$ Availability $\times$ Performance $\times$ Quality

\section{HASIL DAN PEMBAHASAN}

Diperoleh data yang digunakan dalam penelitian ini meliputi data historis waktu operasi Cooling tower unit, data waktu pengukuran,suhu air (inlet), suhu air (outlet), suhu wetbulb, suhu udara sekitar, desain plan efektivitas pendinginan Cooling tower.

Tabel 4.1 Data temperatur Cooling Tower

\begin{tabular}{|c|c|c|c|c|}
\hline \multirow[b]{2}{*}{ NO } & \multicolumn{2}{|c|}{$\mathrm{T}$ (Air) } & \multirow[b]{2}{*}{ wetbulb } & \multirow{2}{*}{$\begin{array}{c}\text { T (Udara) } \\
\text { Inlet } \\
\text { (C) }\end{array}$} \\
\hline & $\begin{array}{l}\text { inlet } \\
\text { (C) }\end{array}$ & $\begin{array}{c}\text { outlet } \\
\text { (C) }\end{array}$ & & \\
\hline 1 & 44.76 & 23.30 & 9.97 & 13.38 \\
\hline 2 & 47.41 & 25.78 & 10.95 & 13.76 \\
\hline 3 & 47.46 & 26.50 & 11.83 & 15.24 \\
\hline 4 & 48.32 & 26.77 & 13.28 & 16.72 \\
\hline 5 & 48.19 & 26.70 & 13.27 & 16.72 \\
\hline 6 & 48.23 & 27.03 & 12.94 & 15.22 \\
\hline 7 & 48.17 & 26.46 & 11.67 & 15.20 \\
\hline 8 & 47.93 & 26.42 & 11.82 & 15.22 \\
\hline 9 & 45.46 & 23.83 & 9.00 & 12.23 \\
\hline 10 & 47.20 & 25.76 & 10.90 & 13.76 \\
\hline 11 & 47.22 & 26.22 & 11.42 & 15.24 \\
\hline 12 & 48.48 & 26.86 & 13.29 & 16.72 \\
\hline 13 & 48.21 & 26.79 & 13.81 & 16.72 \\
\hline 14 & 48.01 & 26.68 & 11.35 & 14.97 \\
\hline 15 & 48.00 & 26.34 & 11.22 & 15.20 \\
\hline 16 & 47.77 & 26.30 & 11.54 & 14.51 \\
\hline 17 & 45.44 & 23.87 & 9.34 & 12.23 \\
\hline 18 & 47.08 & 25.83 & 10.36 & 13.76 \\
\hline 19 & 47.14 & 26.17 & 11.02 & 15.24 \\
\hline 20 & 48.26 & 26.68 & 12.85 & 16.72 \\
\hline 21 & 48.06 & 26.58 & 13.24 & 16.72 \\
\hline
\end{tabular}

\begin{tabular}{|l|c|c|c|c|}
\cline { 5 - 5 } 22 & 47.78 & 26.43 & 11.32 & 13.71 \\
\hline 23 & 47.97 & 26.24 & 11.13 & 15.20 \\
\hline 24 & 47.44 & 25.99 & 11.62 & 15.22 \\
\cline { 5 - 5 } 25 & 45.51 & 23.91 & 9.27 & 12.23 \\
\hline 26 & 47.09 & 25.85 & 10.12 & 13.76 \\
\hline 27 & 47.05 & 26.06 & 11.06 & 13.93 \\
\hline 28 & 48.21 & 26.62 & 12.15 & 15.71 \\
\hline 29 & 48.11 & 26.59 & 13.21 & 16.72 \\
\hline 30 & 47.52 & 26.23 & 10.34 & 13.71 \\
\hline 31 & 47.82 & 26.14 & 10.53 & 13.90 \\
\hline 32 & 47.45 & 26.01 & 10.72 & 13.86 \\
\cline { 5 - 5 } & 45.46 & 23.84 & 9.42 & 12.23 \\
\hline 34 & 47.07 & 25.83 & 10.20 & 13.76 \\
\hline 35 & 47.09 & 26.15 & 11.55 & 13.82 \\
\hline 36 & 48.32 & 26.71 & 12.37 & 15.22 \\
\hline 37 & 48.10 & 26.57 & 13.03 & 16.72 \\
\hline 38 & 47.32 & 26.02 & 11.30 & 13.71 \\
\hline 39 & 47.61 & 25.89 & 10.22 & 13.70 \\
\hline 40 & 47.50 & 26.06 & 11.17 & 13.92 \\
\cline { 5 - 5 } & 45.54 & 23.99 & 12.00 & 14.29 \\
\hline 42 & 46.94 & 25.90 & 14.16 & 16.85 \\
\hline 43 & 47.16 & 26.20 & 13.97 & 16.50 \\
\hline 44 & 48.47 & 26.88 & 16.12 & 19.02 \\
\hline 45 & 48.02 & 26.59 & 15.77 & 18.88 \\
\hline 46 & 47.41 & 26.12 & 15.22 & 17.92 \\
\hline 47 & 47.77 & 26.09 & 14.67 & 17.44 \\
\hline 48 & 47.21 & 25.84 & 17.26 & 20.19 \\
49 & 46.15 & 24.59 & 16.54 & 19.55 \\
\hline 50 & 47.04 & 26.00 & 20.14 & 23.03 \\
\hline & & & & \\
\hline
\end{tabular}

Water flow inlet, Suhu air masuk/sebelum didinginkan cooling tower. Water flow outlet, Suhu air keluar/sesudah didinginkan cooling tower. Wetbulb, Temperatur yang ditunjukan oleh thermometer yang dibungkus kain atau kapas basah yang digunakan untuk menghilangkan radiasi panas dan ad aliean udara yang melaluinya. Air flow inlet, Suhu udara sekitar yang ada di sekitar Cooling tower 
Tabel 4.2 Data Range, Approach dan Efektivitas

\begin{tabular}{|c|c|c|c|}
\hline waktu & Range & approach & Presentase efektivitas \\
\hline jam 01.00 & 21.44 & 14.84 & 59.10 \\
\hline jam 02.00 & 21.44 & 14.54 & 59.60 \\
\hline jam 03.00 & 21.45 & 14.53 & 59.61 \\
\hline jam 04.00 & 21.42 & 14.62 & 59.44 \\
\hline jam 05.00 & 21.42 & 15 & 58.8 \\
\hline jam 06.00 & 21.43 & 14.73 & 59.26 \\
\hline jam 07.00 & 21.36 & 11.05 & 65.9 \\
\hline jam 08.00 & 21.36 & 6.77 & 75.94 \\
\hline jam 09.00 & 21.47 & 5.21 & 80.48 \\
\hline jam 10.00 & 21.55 & 5.2 & 80.55 \\
\hline jam 11.00 & 21.35 & 5.94 & 78.23 \\
\hline jam 12.00 & 21.21 & 6.15 & 77.51 \\
\hline jam 13.00 & 21.3 & 5.9 & 78.3 \\
\hline jam 14.00 & 21.23 & 5.73 & 78.73 \\
\hline jam 15.00 & 21.24 & 7.04 & 75.11 \\
\hline jam 16.00 & 21.35 & 8.63 & 71.2 \\
\hline jam 17.00 & 21.39 & 11.16 & 65.72 \\
\hline jam 18.00 & 21.37 & 12.77 & 62.59 \\
\hline jam 19.00 & 21.24 & 13.44 & 61.24 \\
\hline jam 20.00 & 21.27 & 13.84 & 60.59 \\
\hline jam 21.00 & 21.3 & 14.22 & 59.97 \\
\hline jam 22.00 & 21.37 & 14.38 & 59.78 \\
\hline jam 23.00 & 21.37 & 14.15 & 60.16 \\
\hline jam 24.00 & 21.44 & 14.24 & 60.1 \\
\hline
\end{tabular}

Perhitungan Range menggunakan rumus digambarkan dalam diagram berikut :

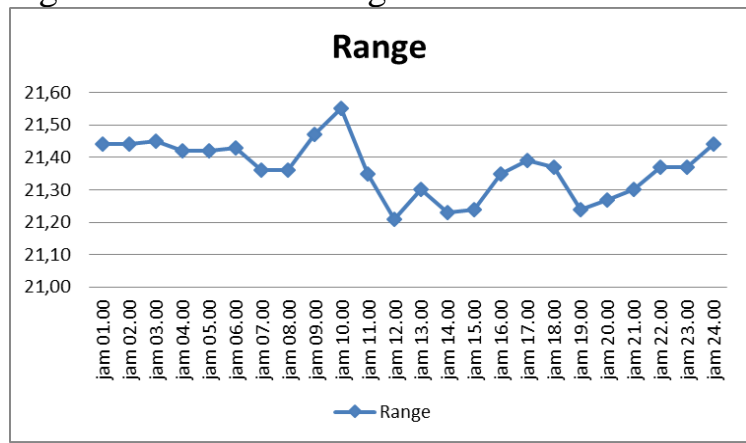

Gambar 4.1 Nilai Range

Nilai Range dalam satuan $\left({ }^{\circ} \mathrm{C}\right)$ diperoleh dari temperatur air masuk $\left({ }^{\circ} \mathrm{C}\right)$ - temperatur air keluar $\left({ }^{\circ} \mathrm{C}\right)$

Perhitungan Approach ditunjukkan dalam diagram berikut:

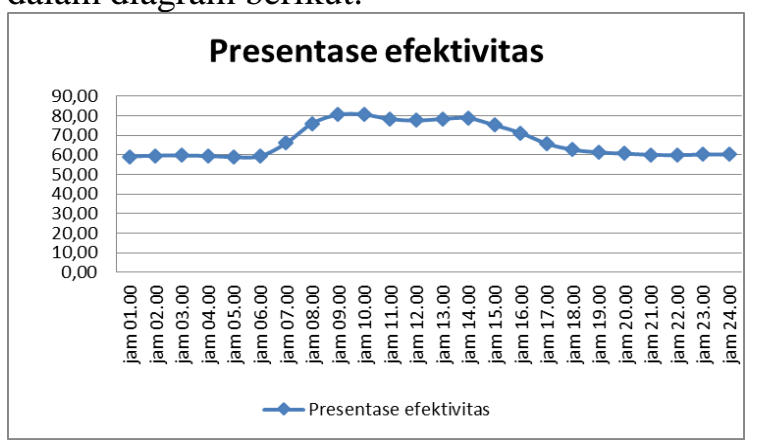

Gambar 4.2 Nilai Approach
Nilai Approach dalam satuan $\left({ }^{\circ} \mathrm{C}\right)$ diperoleh dari temperatur air keluar $\left({ }^{\circ} \mathrm{C}\right)$ - temperatur wet bulb $\left({ }^{\circ} \mathrm{C}\right)$

Perhitungan efektivitas pendinginan ditunjukkan dalam diagram berikut :

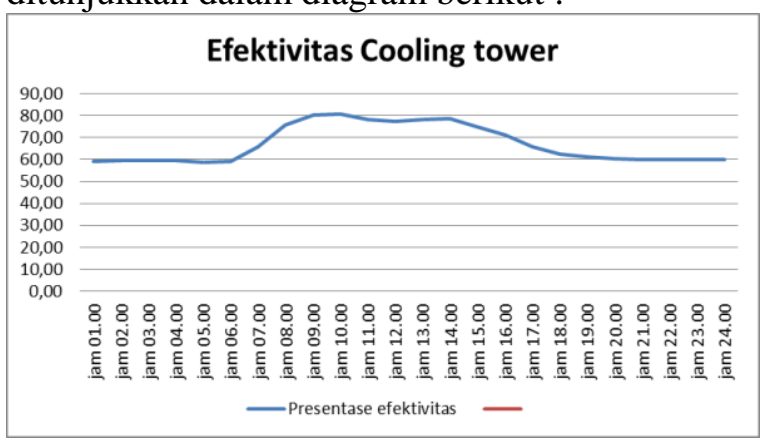

Gambar 4.3 Nilai Efektivitas

Nilai efektivitas diperoleh dengan cara : Efektivitas pendinginan $\%=$ $\frac{\text { Range }}{\text { (Range }+ \text { Approach })} \times 100 \%$

Perhitungan Performance Efficiency untuk yaitu :

Perfomance Rate

$$
\begin{gathered}
=\frac{\text { actual output }}{\text { plan }} \times 100 \% \\
\text { Perfomance Rate }=\frac{327 \text { Ton }}{339 \text { Ton }} \times 100 \% \\
=96,46 \%
\end{gathered}
$$


Analisis produktivitas dilakukan dengan tujuan untuk mengetahui seberapa efektif mesin terebut dapat beroperasi dan mendapat usulan perbaikan terhadap mesin dan kinerja operator. Menurut standar yang dikeluarkan oleh Japanese Institute of Plant Maintenance, meliputi:
1. Availability Rate
$=90 \%$ atau lebih
2. Performance Rate
$=95 \%$ atau lebih
3. Rate of Quality $\quad=99 \%$ atau lebih
4. Overall Equipment Effectiveness = $85 \%$ atau lebih

Jika nilai tersebut sama atau lebih dari standar yang telah ditetapkan, maka mesin tersebut sudah dikatakan mampu bekerja dengan maksimal.

Availability rate merupakan suatu rasio yang menggambarkan pemanfaatan waktu yang tersedia untuk kegiatan operasi mesin. Hasil perhitungan terhadap mesin diperoleh presentasi availability rate sebesar 90,13\%. Performance Rate merupakan suatu rasio yang menggambarkan kemampuan dari peralatan dalam menghasilkan barang atau produk, sedangkan Rate Of Quality adalah rasio yang menggambarkan kemampuan peralatan dalam menghasilkan produk sesuai standar. Hasil perhitungan Performance rate sebesar 88,50\%. Nilai Overall Equipment Effectiveness (OEE) pada mesin diperoleh $>86 \%$.

\section{KESIMPULAN}

Berdasarkan pengolahan data analisa hasil penelitian disimpulkan yaitu :

1. Performance Efficiency sebesar 96,46\% artinya mesin Cooling Tower masih efektif dan berkinerja baik.

2. Nilai Overall Equipment Effectiveness (OEE) pada periode penelitian sudah memenuhi standar world class yaitu $>85 \%$.

3. Hasil penelitian ini menjadi sumber informasi tentang kondisi mesin dan dapat dijadikan acuan untuk melakukan perawatan preventif.

\section{UCAPAN TERIMA KASIH}

Ucapan terima kasih kepada pihak PT Star Energy Wayang Windu Ltd yang telah memberikan ijin untuk melakukan penelitian.

\section{DAFTAR PUSTAKA}

Ade, M. and Muhsin, A. (2017) 'ANALISIS BEBAN KERJA MEKANIK PADA
DEPARTEMEN PLANT DENGAN METODE WORK SAMPLING ( STUDI KASUS PADA PT XYZ )', Jurnal (OPSI) Optimasi Sistem Industri, 10(1), pp. 35-42. Available at: http://jurnal.upnyk.ac.id/index.php/opsi/ article/view/2165.

Effendi, A. and Wirza, R. (2013) 'PERENCANAAN SISTEM SCADA COOLING TOWER MENGGUNAKAN SIEMENS SIMATIC STEP 7 DAN WINCC Fakultas Teknologi Industri - Intitut Teknologi Padang', TEKNOIF, 1(1), pp. 6-14. doi: 10.1080/09637486.2017.1353954.

Handoyo, Y. (2015) 'Analisis Performa Cooling Tower LCT 400 Pada P.T. XYZ, Tambun Bekasi', Jurnal Ilmiah Teknik Mesin, 3(1), pp. 38-52. Available at: https://media.neliti.com/media/publicati ons/97640-ID-analisis-performacooling-tower-lct-400.pdf.

Hapsari, N., Amar, K. and Rahadian, Y. (2012) 'Pengukuran Efektivitas Mesin Dengan Menggunakan Metode Overall Equipment Effectiveness (Oee) Di Pt. Setiaji Mandiri', Spektrum Industri, 10(2), pp. 108-199.

Muhsin, A. (2016) 'ANALISIS PERFORMANSI DEPARTEMEN MACHINNING MENGGUNAKAN METODE OVERALL EQUIPMENT EFFECTIVENES ( OEE ) ( Studi Kasus pada Perusahaan Pengecoran Logam XYZ )', OPSI (Optimasi Sistem Industri), 9(1), pp. 16-23. Available at: http://jurnal.upnyk.ac.id/index.php/opsi/ article/view/2170.

Muhsin, A. and Syarafi, I. (2018) 'ANALISIS KEHANDDALAN DAN LAJU KERUSAKAN PADA MESIN CONTINUES FRYING ( STUDI KASUS : PT XYZ ) Abstrak b . Data Waktu Kerusakan a . Data Komponen Kritis c . Data Waktu Perbaikan d. Pengolahan Data Menentuan distribusi yang paling sesuai dengan karakteristi', Jurnal (OPSI) Optimasi Sistem Industri, 11(1), pp. 28-34. Available at: http://jurnal.upnyk.ac.id/index.php/opsi/ article/viewFile/2200/1932.

Ningrum, N. S. and Muhsin, A. (2016) 'LINE MACHINING PROPELLER SHAFT UNTUK PRODUK FLANGE 
MENGGUNAKAN

OVERALL

METODE

EFFECTIVENESS ( OEE ) ( STUDI

KASUS DI PT HINO MOTORS

MANUFACTURING INDONESIA )',

Jurnal Optimasi Sistem Industri, 9(2),

pp. 109-118. Available at: http://jurnal.upnyk.ac.id/index.php/opsi/ article/view/2167.

Wahyuni, M. F. (2015) 'Analisis nilai', Jurnal Ilmiah Universitas Bakrie, 3(2). Available at: http://journal.bakrie.ac.id/index.php/jurn al_ilmiah_ub/article/view/957.

Wibisono, Y. (2005) 'PENDINGIN TIPE INDUCED COUNTER FLOW Performance $\mathrm{C}$ omparison of $\mathrm{C}$ ooling $\mathrm{T}$ ower F iller Used in the Induced Counter Flow Type Cooling Tower System', Jurnal Teknologi Pertanian, 6(3), pp. 152-162. Available at: http://download.garuda.ristekdikti.go.id/ article.php?article $=309498 \&$ val $=7353 \&$ title=Performance Comparison of Cooling Tower Filler Used in the Induced Counter Flow Type Cooling Tower System.

Yulianto, S. and Urbiantoro, A. (2013) 'Perancangan cooling tower untuk alat penukar kalor shell and tube kapasitas skala laboratorium', SINTEK, 7(1), pp. $1-11$. 